\title{
DEPENDÊNCIA DE SMARTPHONE: INVESTIGANDO A REALIDADE DE UMA PRESTADORA DE SERVIÇO DO SISTEMA "S"
}

SMARTPHONE DEPENDENCY: INVESTIGATING THE REALITY OF AN "S" SYSTEM SERVICE PROVIDER

\section{Fernanda Da Cunha Ortega', Kathiane Benedetti Corso², Martiele Gonçalves Moreira ${ }^{3}$}

RECEBIDO EM: 11/03/2019 | ACEITO EM: 02/04/2020

DOI: $10.5902 / 2317175837257$

\section{RESUMO}

Este estudo tem como objetivo verificar de que forma o uso excessivo de smartphone pode impactar na vida profissional e pessoal dos colaboradores do Sistema "S" em uma cidade do interior do RS. Este estudo do tipo descritivo, caracteriza-se como uma pesquisa de método misto. A presença de colaboradores com dependência de smartphone do tipo leve foi constatada através do instrumento SAS, desenvolvido por Kwon et al. (2013). A maioria foi classificada como "Normal", por meio da aplicação do instrumento quantitativo, não sendo dependentes do aparelho. Quanto aos impactos do uso do smartphone, foram observados qualitativamente por meio de entrevistas, danos físicos, e danos psicológicos, como ansiedade pela falta do aparelho e dificuldade de concentração durante a execução de tarefas.

Palavras-chave: Dependência; Smartphone; Tecnologia móvel.

1 Graduada em Administração pela Universidade Federal do Pampa.

2 Professora Adjunta na área de Administracão da Universidade Federal do Pampa - UNIPAMPA. Doutora em Administração pelo PPGAJEAUFRGS (2013). Mestre em Administração pela UFSM (2009). Possui Graduação em Administração pela UFSM (2006).

3 Administradora pela Universidade Federal do Pampa. Atualmente é doutoranda do Programa de Pós-Graduação em Administração da Universidade Federal de Santa Maria. 


\section{ABSTRACT}

This study aims to verify if the excessive use of smartphones can impact the professional and personal life of the employees of the "S" System in a city in the interior of the RS. This study of type descriptive is characterized by a mixed method of inquiry. The presence of employees with dependence on light-weight smartphones was verified through the SAS instrument developed by Kwon et al. (2013). Most were classified as "Normal", through the application of the quantitative instrument. Regarding the impacts of the use of the smartphone, physical damages and psychological damages, such as anxiety due to lack of device and difficulty of concentration during the execution of tasks, were observed qualitatively.

Keywords: Dependence; Smartphone; Mobile technology.

\section{Introdução}

Os smartphones, modernos telefones móveis, são aparelhos multifuncionais, que disponibilizam infinitas opções de serviços, aplicativos e possibilidades de tornar a vida de quem os utiliza mais prática. Com o avanço da tecnologia móvel, e pode-se destacar o avanço da internet paralelamente, os telefones móveis ganharam outras funções e principalmente novos conceitos. Conforme sua evolução foi ocorrendo, os celulares passaram a agrupar as funções de vários outros aparelhos, tornando-se mais atrativos para os usuários.

Hoje os smartphones dispõem de muitas funções que simplificam o acesso a recursos no dia-a-dia dos usuários. Lemos (2004) usa o termo "teletudo" para definir esses novos aparelhos que expressam, energicamente, a convergência digital para a gestão móvel e tecnológica do dia a dia. Onde ganhou muito espaço na vida de todos, e para Gonçalves (2012), hoje se percebe uma grande necessidade de se conectar, algo indispensável para se sentir incluído em um mundo que cada vez mais se torna digital e interativo.

Considerando a enorme popularização do smartphone e o uso constante, e por vezes abusivo, estudos vêm sendo realizados acerca desse novo cenário digital. Conforme Mark, Gudith e Klocke (2008) o uso abusivo do smartphone tende a comprometer a concentração e desempenho dos usuários no âmbito profissional. Deste modo, viu-se a necessidade de analisar os impactos desses dispositivos na vida de quem os utiliza.

$\mathrm{Na}$ atualidade, as organizações também necessitam dos recursos que o smartphone dispõe e ele tem sido uma ferramenta facilitadora para comunicação entre gestores, colaboradores e clientes. Dentre as várias organizações que incorporam o smartphone no dia a dia dos colaboradores, o Sistema "S" pode ser citado. Sistema "S" é a expressão que determina o conjunto de entidades corporativas focadas para a capacitação profissional, consultoria, assistência social, assistência técnica e pesquisa, têm origens comuns e propriedades organizacionais parecidas (SEBRAE, 2016).

Desse modo, devido à relevância do assunto abordado e a escassez de 
pesquisas sobre o tema dependência de smartphone no Brasil, viu-se a necessidade de acercar-se dessa questão e procurar verificar fatores que geram tal problemática. Logo, busca-se saber: De que forma o uso excessivo de smartphone pode impactar na vida profissional e pessoal dos colaboradores do Sistema "S"? Para tanto se pretende verificar de que forma este uso pode impactar na vida profissional e pessoal desses colaboradores. Estas ações prejudicam o andamento das atividades laborais, como já foi comprovado, logo, se torna relevante aprofundar os estudos sobre dependência de smartphone e os impactos sofridos pelos seus usuários. Sendo relevante também para as organizações a fim de compreender este novo cenário que pode vir a existir no ambiente laboral.

\section{Referencial teórico}

2.1 Dependência de smartphone

Diante da dependência de internet e com a modernização dos apareIhos celulares, percebeu-se que o smartphone agregado ao fato da facilidade de conexão móvel poderia também causar dependência. Picon et al. (2015) assegura que a utilização de smartphones oferece um diferencial quando comparado a outros aparelhos similares, pois tem a particularidade de ser tão móvel ao ponto de sempre estar ao alcance do usuário, independente de onde esteja. Os smartphones são indiscutivelmente computadores pessoais, tornando-os muito atraentes a determinados usuários até mesmo por minimizar algumas sensações desagradáveis, como solidão, frustração e tédio. Esses benefícios trouxeram grande conveniência para a sociedade moderna, porém, os smartphones compartilham a maior parte das características da internet, assim, a dependência de smartphones é fortemente passível de desencadear problemas físicos e psicológicos da mesma forma que a dependência da internet (KWON et al., 2013a).

Kwon et al. (2013a) acreditam que decorrências adversas causadas pelo uso abusivo de smartphones podem ser apontadas facilmente nas pessoas de hoje. É muito comum assistir vídeos no smartphone enquanto se atravessa a rua, sem nem mesmo conferir o sinal de trânsito; pessoas distraídas com um smartphone enquanto estão ao volante podem provocar acidentes de trânsito; e as crianças em idade escolar são muito vulneráveis a se tornarem viciadas em jogos de smartphone, assim como a jogos na internet.

O Hospital Sírio Libanês (2013), em publicação periódica, aponta 6 sinais que podem ser determinados como os sinais de dependência de smartphone mais frequentes. Em situação de dependência o usuário tem seus pensamentos e comportamentos dominados; a pessoa sente uma sensação de prazer ao utilizar o aparelho, certa euforia ou alívio durante o período em que utiliza; sente a necessidade de utilizar cada vez mais o aparelho para alcançar a sensação de prazer em que obtinha no início; sente desconforto enquanto não 
pode utilizá-lo, semelhante a sintomas de abstinência; o celular passa a gerar conflitos com as pessoas próximas; o usuário tenta diminuir a frequência de uso, porém, não obtém êxito e normalmente volta a utilizar o aparelho ainda de forma mais acentuada.

Rocha et al. (2015) afirmam que há, até mesmo, um grupo de síndromes modernas pautadas pela psicologia que delineiam certas implicações negativas causadas pelo uso abusivo de internet, e destaca a nomofobia (o medo absurdo de sair sem celular), e a Fear Of Missing Out (FOMO), traduzida como medo de perder alguma coisa, que consiste no medo de estar desinformado de determinado fato ou notícia veiculada virtualmente (ROCHA et al., 2015).

De acordo com Mok et al. (2014), o uso abusivo de smartphones pode acarretar problemas de comportamento tais como, dificuldade adaptativa assim como em distúrbios de comando de impulsos em jogos de azar em geral ou distúrbios patológicos; pode influênciar no desempenho escolar ou no trabaIho; dificuldade na convivência social e na vida real; alterar o desempenho acadêmico, ocasionar dificuldades de relacionamento, e resultar em problemas de saúde física, abrangendo visão nebulosa e dor nos pulsos ou atrás do pescoço.

Em pesquisa realizada por Borges e Joia (2013), verificou-se que a dependência de smartphone também pode ser frequente em profissionais. Por meio da análise das ações realizadas a partir dos smartphones dos pesquisados, viu-se a prática frequente de envio e/ou respostas de e-mails de assuntos profissionais aos fins de semana. Esses dados confirmam que, mesmo o smartphone proporcionando independência ao usuário, também resulta em certa dependência, pois o usuário passa a utilizar o aparelho demasiadamente. Vale ressaltar que a dependência de smartphone não está restrita a nenhum grupo específico de usuários, não está ligado à idade, sexo ou outras particularidades, todos são passíveis de desenvolver tal síndrome.

Percebe-se que este sentimento vem sendo pesquisado recentemente em campo internacional, na busca de desenvolver instrumentos capazes de medir o uso excessivo do smartphone e as causas dessa síndrome. Essa patologia vem aos poucos chamando a atenção e de certa forma preocupando os pesquisadores, pois é notável a crescente utilização dos smartphones (LOPEZ-FERNANDEZ, 2017). E se torna importante entender como essa dependência ocorre, quais seus impactos e como a organização em que o indivíduo trabalha pode lidar com esses novos fatos da atualidade.

Buscando demonstrar alguns dos impactos da dependência de smartphone, destacados por diversos autores, construiu-se a Quadro 1 que aborda o julgamento do principal pesquisador do tema no tocante dos malefícios dessa patologia, Kwon et al. (2013a) e autores como Fortim (2013), Mok et al. (2014), Picon et al. (2015) que também destacam os principais impactos. 
Quadro 1 - Impactos da dependência de smartphone

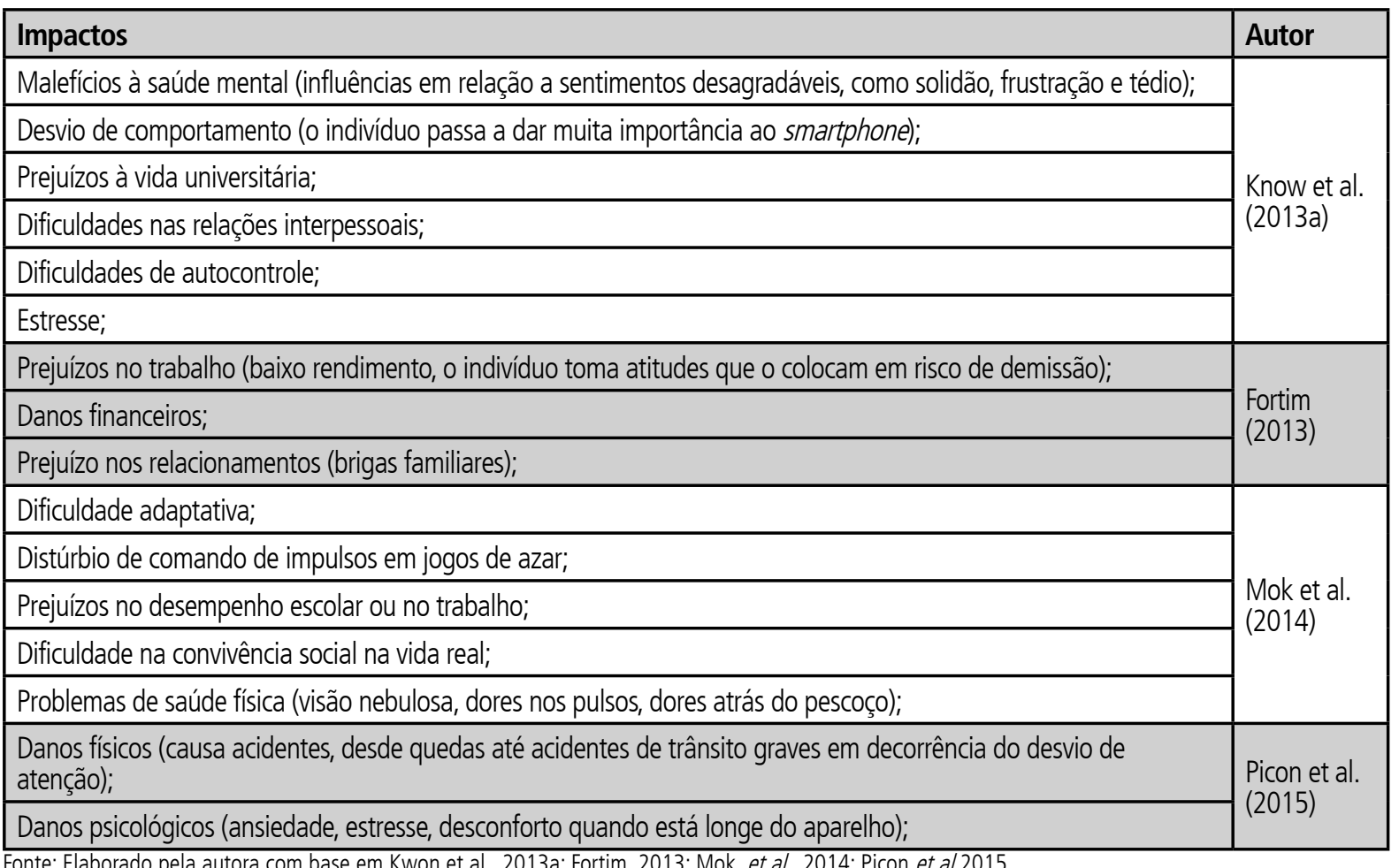

Nesse sentido, sabendo das implicações causadas pelo smartphone na vida dos usuários, verifica-se a incidência dessa patologia em diferentes perfis. Segundo Kwon et al. (2013b) a dependência de smartphone apresenta maior prevalência em adolescentes e jovens de até vinte anos do que naqueles indivíduos na faixa dos trinta a quarenta anos. Pesquisas realizadas por universitários da Coréia do Sul têm confirmado a relação de dependência de smartphones com os malefícios à saúde mental, a vida universitária, relações interpessoais, autocontrole e estresse. A Coréia mostrou que os adolescentes podem apresentar maior probabilidade de desenvolver problemas com o uso de smartphones do que os adultos pela forma de uso, por utilizarem os smartphones como uma alternativa para acessar a internet.

Em julho de 2014, psicólogos da Universidade de Gênova, na Itália, solicitaram formalmente que a Nomofobia (Dependência de smartphone) passasse a pertencer ao grupo de patologias no manual de DSM-V devido ao grande crescimento de pessoas que tem apresentado a doença. Calcula-se que $20 \%$ da população mundial sofram da doença, a maior parte, jovens entre 18 e 24 anos (CENTRO UNIVERSITÁRIO METODISTA, 2014).

Para Ribeiro e Silva (2015), as gerações mais novas tendem a utilizar mais frequentemente tecnologias como smartphones e tablets, contrariando a geração de mais idade, onde um percentual pequeno possui. Mais comumente utilizam celulares simples, apenas com recursos para envio de Short Message Service (SMS) ou para efetuar ligações, sem aplicativos ou acesso à internet. 
Contrapondo-se às gerações mais novas, poucos não possuem celulares capazes de suportar aplicativos.

Picon et al. (2015) cita que mulheres também são alvos preocupantes, pois há uma prevalência de usuários de smartphones do sexo feminino. $\mathrm{O}$ autor ainda destaca que o perigo de dependência está relacionado com certas propriedades específicas, como o uso excessivo de redes sociais e a quantidade de mensagens de texto encaminhadas, elevados níveis de tédio e com baixa autoestima. Sentimentos de isolamento, busca por aceitação e neuroticismo Ação de quem se comporta de maneira nervosa, são classificados como fatores de risco. Ainda, o uso abusivo de smartphones pode ser associado a altos níveis de ansiedade, depressão e alexitimia - Dificuldade em verbalizar emoções e descrever sentimentos.

Posto isso, nota-se a abrangência de causas e efeitos que o uso do smartphone pode afetar no dia a dia dos indivíduos, tanto na esfera do trabalho quanto na esfera pessoal. Reforçando a relevância do tema aqui apresentado.

\section{Método do estudo}

O tipo de pesquisa adotada neste trabalho é a descritiva, pois busca verificar características presentes, em relação ao uso de smartphone, no grupo pesquisado. O método de pesquisa adotado para esta investigação foi o misto explanatório sequencial, através da divisão da pesquisa em duas etapas (quantitativa e qualitativa). O método misto é um procedimento que emprega os pontos fortes de pesquisas quantitativa e qualitativa, agrupando tanto a necessidade de explorar quanto a de explicar. Creswell (2007) define o método misto explanatório sequencial como uma metodologia caracterizada pela coleta e análise de dados quantitativos, quando na primeira fase de uma pesquisa, seguido de coleta e análise de dados qualitativos em um segundo momento da investigação, esse é desenvolvido sobre os resultados quantitativos iniciais. Há uma consideração maior que é caracteristicamente conferida aos dados quantitativos, e a ligação dos dados acontece quando os resultados quantitativos iniciais acarretam a coleta de dados qualitativos na etapa secundária. Desse modo, os dados das duas formas estão isolados, porém, conectados.

Para a etapa quantitativa, foi aplicado o questionário de mensuração de dependência de smartphone - SAS (KWON et al., 2013b), aos 60 colaboradores do Sistema " $S$ " validado originalmente pelo autor na língua inglesa, traduzido para o português e adaptado pelos autores desta pesquisa. Quanto às adaptações realizadas no questionário original, essas estão relacionadas a ajustes de contexto de pesquisa e a inclusão do aplicativo WhatsApp, que na versão original não foi abordado e julgou-se pertinente citá-lo, diante da grande popularidade mundial e nacional do aplicativo. A versão traduzida do questionário, antes de sua aplicação, foi enviada para análise e correção da tradução por dois especialistas da língua inglesa, bem como foi realizado um pré-teste. 
O questionário é composto por 33 questões com pontuação individual de 1 a 6 , onde 1 equivale a "discordo totalmente" e 6 equivale a "concordo totalmente". Dos resultados quantitativos, foi definido pelos autores que do somatório da pontuação resultante do questionário SAS, que em sua versão original não apresenta intervalo de pontuação, o usuário poderia enquadrar-se em um dos quatro grupos: Normal, de 35 a 75 pontos; Leve, de 76 a 116 pontos; Moderada, de 117 a 157 pontos e Grave, de 158 a 198 pontos. O critério para tal divisão foi baseado no Internet Addiction Test (IAT) de Young (2011), teste de dependência de internet, que possui também quatro intervalos nominados dessa mesma forma, porém, com pontuações distintas, já que o número de questões não é compatível com o SAS. A finalidade do instrumento é medir através da contagem de pontos, o nível de dependência do indivíduo respondente, podendo ele ser enquadrado em um dos quatro graus possíveis (Normal, Leve, Moderada e Grave). Dessa forma, na etapa quantitativa, os dados extraídos a partir do questionário de Kwon et al. (2013a) foram analisados através de estatística descritiva com o auxílio de planilhas eletrônicas e software estatístico SPSS 20.0, sendo que dos 60 colaboradores 37 responderam de forma correta possibilitando realizar as análises pertinentes.

$\mathrm{Na}$ etapa qualitativa, foram feitas entrevistas com colaboradores do Sistema " $S$ " da cidade pesquisada, que foram selecionados observando o nível de pontuação resultante do questionário. Aqueles que obtiveram pontuação, que os caracterizavam com algum nível de dependência, foram convidados a participar dessa fase. Dentre os respondentes do questionário treze deles foram identificados com nível leve de dependência, sendo estes os convidados a prosseguir a pesquisa. Porém, obteve-se o aceite de apenas três participantes que se disponibilizaram a prosseguir com a pesquisa em sua etapa qualitativa.

Para tal, foi elaborado um roteiro de entrevista estruturado, com base no referencial teórico deste trabalho. A entrevista estruturada segue um roteiro elaborado e é realizada com pessoas escolhidas de acordo com um plano (MARCONI e LAKATOS, 2009). Para realizar as análises, adotou-se a técnica de análise de discurso que segundo Orlandi (2003), essa técnica considera a fala do indivíduo no seu contexto possibilitando uma análise aprofundada dos discursos dos participantes da pesquisa.

\section{Apresentação e discussão dos resultados}

4.1 Caracterização dos respondentes obtida na aplicação dos questionários

Participaram da pesquisa 37 dos 60 colaboradores das empresas Sesc, Senac e Sebrae, que compõem o Sistema "S" de uma cidade do interior do RS com aproximadamente 80 mil habitantes (IBGE, 2016), onde o sexo predominante foi o feminino (67,6\%). Quanto à idade dos pesquisados, essa variou entre 20 a 53 anos, sendo a maioria natural da cidade na qual o questionário foi aplicado. 
Em suma, o perfil da população é de indivíduos com idade média de 34 anos, com nível de escolaridade alto, são casados, moram com até 3 pessoas e a renda predominante é de 2 salários mínimos vigentes. Os colaboradores disseram que utilizam seus smartphones no trabalho, porém, disseram usá-lo por um período maior em suas casas, para acessar principalmente redes sociais. Tendo como prioridade o acesso aos aplicativos de bate-papo (Whatsapp) e email. De forma curiosa, apenas um participante afirma utilizar do smartphone como meio prioritário para realizar ligações, percebe-se que os demais não consideram as ligaçõs como uso primário do smartphone.

4.2 Análise do nível de dependência de smartphone a partir do instrumento SAS

Nesta seção, serão realizadas as análises das questões que compõem o instrumento de mensuração de dependência de smartphone. As perguntas estão organizadas através de uma escala intervalar de 6 pontos, no qual, o número respondente expõem seu grau de concordância, sendo: 1= "Discordo totalmente (DT); $2=$ Discordo (D); 3= Discordo Parcialmente (DP); $4=$ Concordo Parcialmente (CP); $5=$ Concordo (C); e $6=$ Concordo totalmente (CT). Este instrumento buscou verificar a existência de indivíduos dependentes do aparelho entre a população pesquisada, assim como o nível de dependência presente em cada sujeito. Os resultados obtidos serão explanados no decorrer das análises por meio de Quadros ilustrativas, ressaltando que está em destaque a maior frequência em cada questão.

Observando as frequências de respostas das questões de 1 a 5 (Quadro 2), que estão relacionadas a concentração no trabalho e danos físicos ocasionados pelo uso do smartphone, como tontura, visão turva, dor nos pulsos, dor na parte trás do pescoço, cansaço e falta de sono adequado, verifica-se que a maioria dos sujeitos "discorda totalmente", o que significa que não sentem os impactos físicos citados por Mok et al. (2014), e conseguem administratar o uso do smartphone de modo a não prejudicar o trabalho.

Quadro 2 - Variáveis do SAS e frequência

\begin{tabular}{|c|c|c|c|c|c|c|c|}
\hline Variáveis & & \begin{tabular}{|l|} 
Frequência/ \\
Percentual
\end{tabular} & & & & & \\
\hline & & DT & $D$ & DP & $C P$ & $C$ & $\mathrm{CT}$ \\
\hline \multirow{2}{*}{1} & \multirow{2}{*}{$\begin{array}{l}\text { Deixei de fazer trabalho } \\
\text { planejado por causa do uso } \\
\text { do smartphone. }\end{array}$} & 24 & 8 & 4 & 0 & 1 & 0 \\
\hline & & $64,9 \%$ & $21,6 \%$ & $10,8 \%$ & $0,0 \%$ & $2,7 \%$ & $0,0 \%$ \\
\hline \multirow[b]{2}{*}{2} & \multirow{2}{*}{$\begin{array}{l}\text { Tenho dificuldade de } \\
\text { concentração no meu } \\
\text { trabalho, enquanto faço } \\
\text { tarefas, devido ao uso do } \\
\text { smartphone. }\end{array}$} & 25 & 9 & 1 & 2 & 0 & 0 \\
\hline & & $67,6 \%$ & $24,3 \%$ & $2,7 \%$ & $5,4 \%$ & $0,0 \%$ & $0,0 \%$ \\
\hline
\end{tabular}




\begin{tabular}{|c|c|c|c|c|c|c|c|}
\hline \multirow[b]{2}{*}{3} & \multirow{2}{*}{$\begin{array}{l}\text { Sinto tontura ou visão turva } \\
\text { devido ao uso excessivo de } \\
\text { smartphone. }\end{array}$} & 21 & 13 & 1 & 1 & 1 & 0 \\
\hline & & $56,8 \%$ & $35,1 \%$ & $2,7 \%$ & $2,7 \%$ & $2,7 \%$ & $0,0 \%$ \\
\hline \multirow[b]{2}{*}{4} & \multirow{2}{*}{$\begin{array}{l}\text { Sinto dor nos pulsos ou na } \\
\text { parte de trás do pescoço } \\
\text { enquanto estou usando o } \\
\text { smartphone. }\end{array}$} & 20 & 9 & 4 & 1 & 3 & 0 \\
\hline & & $54,1 \%$ & $24,3 \%$ & $10,8 \%$ & $2,7 \%$ & $8,1 \%$ & $0,0 \%$ \\
\hline \multirow[b]{2}{*}{5} & \multirow{2}{*}{$\begin{array}{l}\text { Sinto-me cansado e com } \\
\text { falta de sono adequado, } \\
\text { devido ao uso excessivo de } \\
\text { smartphone. }\end{array}$} & 21 & 15 & 0 & 0 & 0 & 1 \\
\hline & & $56,8 \%$ & $40,5 \%$ & $0,0 \%$ & $0,0 \%$ & $0,0 \%$ & $2,7 \%$ \\
\hline
\end{tabular}

Fonte: Dados da pesquisa.

As questões 6, 7 e 8 (Quadro 3) abordavam sentimentos do usuário de smartphone enquanto este faz uso do aparelho, questionava-se se o sujeito se sente animado, calmo, confortável e confiante, sendo os respondentes concordantes com a questão.

Quadro 3 - Variáveis do SAS e frequência

\begin{tabular}{|c|c|c|c|c|c|c|c|}
\hline Variáveis & & \begin{tabular}{|l|} 
Frequência/ \\
Percentual
\end{tabular} & & & & & \\
\hline & & DT & $D$ & $\mathrm{DP}$ & $C P$ & $C$ & $\mathrm{CT}$ \\
\hline \multirow{2}{*}{6} & \multirow{2}{*}{$\begin{array}{l}\text { Sinto-me calmo ou } \\
\text { confortável usando o } \\
\text { smartphone. }\end{array}$} & 4 & 10 & 1 & 10 & 11 & 1 \\
\hline & & $10,8 \%$ & $27,0 \%$ & $2,7 \%$ & $27,0 \%$ & $29,7 \%$ & $2,7 \%$ \\
\hline \multirow[b]{2}{*}{7} & \multirow{2}{*}{$\begin{array}{l}\text { Sinto-me bem ou } \\
\text { animado enquanto } \\
\text { estou usando o } \\
\text { smartphone. } \\
\end{array}$} & 3 & 7 & 1 & 12 & 13 & 1 \\
\hline & & $8,1 \%$ & $18,9 \%$ & $2,7 \%$ & $32,4 \%$ & $35,1 \%$ & $2,7 \%$ \\
\hline \multirow{2}{*}{8} & \multirow{2}{*}{$\begin{array}{l}\text { Sinto-me confiante ao } \\
\text { usar o smartphone. }\end{array}$} & 3 & 10 & 4 & 10 & 8 & 2 \\
\hline & & $8,1 \%$ & $27,0 \%$ & $10,8 \%$ & $27,0 \%$ & $21,6 \%$ & $5,4 \%$ \\
\hline
\end{tabular}

Na sequência, a questão 9 sugere que o indivíduo é capaz de se livrar do estresse quando está utilizando o smartphone, 16 respondentes dos 37 pesquisados discordaram da sentença, representando 43,2\%. Nas questões $10 \mathrm{e}$ 11, que mediam o grau de concordância dos indivíduos sobre não existir nada mais divertido do que usar o smartphone e de que a vida seria vazia sem ele, os respondentes se apresentam totalmente discordantes dessa questão, assim como nas questões 13, $14,15,16$ e 17. Essa sequencia de questões sugeria, por exemplo, que para o usuário a coisa mais divertida para se fazer é utilizar o smartphone ou que não é capaz de suportar não ter o aparelho. A discordância dos respondentes com as questões do Quadro 4, mostra que para a população pesquisada, o aparelho está em segundo plano, e pode-se concluir que eles não tem problema quanto a concentração em outras atividades por exemplo, ela não é prejudicada em função do smartphone, pelo desejo de utilizá-lo. 
Quadro 4 - Variáveis do SAS e frequência

\begin{tabular}{|c|c|c|c|c|c|c|c|}
\hline Variáveis & & \begin{tabular}{|l|} 
Frequência/ \\
Percentual
\end{tabular} & & & & & \\
\hline & & DT & $D$ & DP & $C P$ & $C$ & CT \\
\hline \multirow{2}{*}{9} & \multirow{2}{*}{$\begin{array}{l}\text { Sou capaz de me livrar } \\
\text { do estresse com o } \\
\text { smartphone. }\end{array}$} & 4 & 16 & 5 & 5 & 5 & 2 \\
\hline & & $10,8 \%$ & $43,2 \%$ & $13,5 \%$ & $13,5 \%$ & $13,5 \%$ & $5,4 \%$ \\
\hline \multirow{2}{*}{10} & \multirow{2}{*}{$\begin{array}{l}\text { Não há nada mais } \\
\text { divertido do que usar } \\
\text { meu smartphone. }\end{array}$} & 16 & 15 & 2 & 3 & 0 & 1 \\
\hline & & $43,2 \%$ & $40,5 \%$ & $5,4 \%$ & $8,1 \%$ & $0,0 \%$ & $2,7 \%$ \\
\hline \multirow{2}{*}{11} & \multirow{2}{*}{$\begin{array}{l}\text { Minha vida seria vazia } \\
\text { sem meu smartphone. }\end{array}$} & 21 & 14 & 2 & 0 & 0 & 0 \\
\hline & & $56,8 \%$ & $37,8 \%$ & $5,4 \%$ & $5,4 \%$ & $0,0 \%$ & $0,0 \%$ \\
\hline \multirow[b]{2}{*}{12} & \multirow{2}{*}{$\begin{array}{l}\text { Sinto-me mais aberto a } \\
\text { novidades enquanto uso } \\
\text { o smartphone. }\end{array}$} & 5 & 11 & 5 & 10 & 6 & 0 \\
\hline & & $13,5 \%$ & $29,7 \%$ & $13,5 \%$ & $27,0 \%$ & $16,2 \%$ & $0,0 \%$ \\
\hline \multirow{2}{*}{13} & \multirow{2}{*}{$\begin{array}{l}\text { Usar o smartphone é a } \\
\text { coisa mais divertida para } \\
\text { fazer. }\end{array}$} & 17 & 15 & 5 & 0 & 0 & 0 \\
\hline & & $45,9 \%$ & $40,5 \%$ & $13,5 \%$ & $0,0 \%$ & $0,0 \%$ & $0,0 \%$ \\
\hline \multirow{2}{*}{14} & \multirow{2}{*}{$\begin{array}{l}\text { Não sou capaz de } \\
\text { suportar não ter um } \\
\text { smartphone. }\end{array}$} & 23 & 11 & 3 & 0 & 0 & 0 \\
\hline & & $62,2 \%$ & $29,7 \%$ & $8,1 \%$ & $0,0 \%$ & $0,0 \%$ & $0,0 \%$ \\
\hline \multirow[b]{2}{*}{15} & \multirow{2}{*}{$\begin{array}{l}\text { Sinto-me impaciente } \\
\text { e irritável quando não } \\
\text { estou segurando meu } \\
\text { smartphone. }\end{array}$} & 23 & 11 & 2 & 1 & 0 & 0 \\
\hline & & $62,2 \%$ & $29,7 \%$ & $5,4 \%$ & $2,7 \%$ & $0,0 \%$ & $0,0 \%$ \\
\hline \multirow[b]{2}{*}{16} & \multirow{2}{*}{$\begin{array}{l}\text { Tenho meu smartphone } \\
\text { em minha mente mesmo } \\
\text { quando não o estou } \\
\text { usando. }\end{array}$} & 23 & 11 & 1 & 1 & 1 & 0 \\
\hline & & $62,2 \%$ & $29,7 \%$ & $2,7 \%$ & $2,7 \%$ & $2,7 \%$ & $0,0 \%$ \\
\hline \multirow[b]{2}{*}{17} & \multirow{2}{*}{$\begin{array}{l}\text { Eu nunca vou deixar de } \\
\text { usar meu smartphone } \\
\text { mesmo quando minha } \\
\text { vida diária já estiver } \\
\text { muito afetada. }\end{array}$} & 25 & 7 & 2 & 3 & 0 & 0 \\
\hline & & $67,6 \%$ & $18,9 \%$ & $5,4 \%$ & $8,1 \%$ & $0,0 \%$ & $0,0 \%$ \\
\hline
\end{tabular}

Fonte: Dados da pesquisa.

A questão de número 18 traz a seguinte afirmação: "Se interrompido enquanto estiver utilizando meu smartphone fico irritado". A grande maioria dos indivíduos, sendo $48,6 \%$ do total, disseram discordar da afirmativa. 0 mesmo ocorreu com a sentença 19, "levo meu smartphone para o banheiro, mesmo quando estou com pressa em chegar lá". A questão 20 sugere que o indivíduo sente-se ótimo conhecendo mais pessoas através do uso do smartphone, a maior frequência foi de $37,8 \%$ no qual concordam parcialmente com a afirmação, como pode ser verificado no Quadro 5. 
Quadro 5 - Variáveis do SAS e frequência

\begin{tabular}{|c|c|c|c|c|c|c|c|}
\hline Variáveis & & $\begin{array}{l}\text { Frequência/ } \\
\text { Percentual }\end{array}$ & & & & & \\
\hline & & DT & $D$ & DP & $C P$ & $C$ & $\mathrm{CT}$ \\
\hline \multirow[b]{2}{*}{18} & \multirow{2}{*}{$\begin{array}{l}\text { Fico irritado se } \\
\text { interronpido } \\
\text { enquanto estou } \\
\text { usando meu } \\
\text { smartphone. } \\
\end{array}$} & 16 & 18 & 1 & 2 & 0 & 0 \\
\hline & & $43,2 \%$ & $48,6 \%$ & $2,7 \%$ & $5,4 \%$ & $0,0 \%$ & $0,0 \%$ \\
\hline \multirow[b]{2}{*}{19} & \multirow{2}{*}{$\begin{array}{l}\text { Levo meu } \\
\text { smartphone para o } \\
\text { banheiro, mesmo } \\
\text { quando estou com } \\
\text { pressa em chegar lá. }\end{array}$} & 16 & 11 & 3 & 5 & 2 & 0 \\
\hline & & $43,2 \%$ & $29,7 \%$ & $8,1 \%$ & $13,5 \%$ & $5,4 \%$ & $0,0 \%$ \\
\hline \multirow[b]{2}{*}{20} & \multirow{2}{*}{$\begin{array}{l}\text { Sinto-me ótimo } \\
\text { conhecendo mais } \\
\text { pessoas através do } \\
\text { uso de smartphone. }\end{array}$} & 7 & 9 & 3 & 14 & 4 & 0 \\
\hline & & $18,9 \%$ & $24,3 \%$ & $8,1 \%$ & $37,8 \%$ & $10,8 \%$ & $0,0 \%$ \\
\hline
\end{tabular}

Fonte: Dados da pesquisa.

As assertivas 21 a 24 abordam o relacionamento na vida real e por meio do smartphone. Em todas as questões mencionadas, o grupo é discordante das questões abordadas. A afirmativa número 25 aborda a questão das redes sociais e o hábito de verificá-las logo após acordar, 35,1\% dos sujeitos disseram concordar. O que vai ao encontro com o que diz Picon et al. (2015), ao mencionar que a forma de operação das redes sociais estimulam o permantente retorno do usuário a elas, causando uma constante vontade de conferir o que está acontecendo em seus perfis, verificados no Quadro 6.

Quadro 6 - Variáveis do SAS e frequência

\begin{tabular}{|c|c|c|c|c|c|c|c|}
\hline Variáveis & & \begin{tabular}{|l|} 
Frequência/ \\
Percentual
\end{tabular} & & & & & \\
\hline & & DT & $D$ & $\mathrm{DP}$ & $C P$ & C & CT \\
\hline \multirow[b]{2}{*}{21} & \multirow{2}{*}{$\begin{array}{l}\text { Sinto que meu relacionamen- } \\
\text { to com meus amigos do smar- } \\
\text { tphone é mais íntimo do que } \\
\text { minhas relações com meus } \\
\text { amigos da vida real. }\end{array}$} & 21 & 8 & 3 & 5 & 0 & 0 \\
\hline & & $56,8 \%$ & $21,6 \%$ & $8,1 \%$ & $13,5 \%$ & $0,0 \%$ & $0,0 \%$ \\
\hline \multirow{2}{*}{22} & \multirow{2}{*}{$\begin{array}{l}\text { Não poder usar meu smar- } \\
\text { tphone é tão doloroso quanto } \\
\text { perder um amigo. }\end{array}$} & 31 & 6 & 0 & 0 & 0 & 0 \\
\hline & & $83,8 \%$ & $16,2 \%$ & $0,0 \%$ & $0,0 \%$ & $0,0 \%$ & $0,0 \%$ \\
\hline \multirow[b]{2}{*}{23} & \multirow{2}{*}{$\begin{array}{l}\text { Sinto que meus amigos do } \\
\text { smartphone me compreen- } \\
\text { dem melhor do que meus } \\
\text { amigos da vida real. }\end{array}$} & 26 & 9 & 2 & 0 & 0 & 0 \\
\hline & & $70,3 \%$ & $24,3 \%$ & $5,4 \%$ & $0,0 \%$ & $0,0 \%$ & $0,0 \%$ \\
\hline \multirow[b]{2}{*}{24} & \multirow{2}{*}{$\begin{array}{l}\text { Constantemente verifico meu } \\
\text { smartphone de forma a não } \\
\text { perder conversas entre outras } \\
\text { pessoas no WhatsApp ou } \\
\text { Facebook. }\end{array}$} & 11 & 11 & 5 & 6 & 4 & 0 \\
\hline & & $29,7 \%$ & $29,7 \%$ & $13,5 \%$ & $16,2 \%$ & $10,8 \%$ & $0,0 \%$ \\
\hline \multirow{2}{*}{25} & \multirow{2}{*}{$\begin{array}{l}\text { Verifico redes sociais, como } \\
\text { WhatsApp, Facebook ou Ins- } \\
\text { taqram, logo após acordar. }\end{array}$} & 7 & 4 & 3 & 8 & 13 & 2 \\
\hline & & $18,9 \%$ & $10,8 \%$ & $8,1 \%$ & $21,6 \%$ & $35,1 \%$ & $5,4 \%$ \\
\hline
\end{tabular}

Fonte: Dados da pesquisa. 
Os próximo respondentes mostrados no Quadro 7, discordam totalmente da alegação da questão 26 que diz: "Prefiro falar com meus amigos no smartphone do que sair com meus amigos na vida real ou com outros membros da minha família". Em relação a duração da bateria de seus aparelhos smartphones, $48,6 \%$ dos respondentes discordam que ela não dure todo dia quando está totalmente carregada, o que afirma a frase 27. Quanto ao tempo de uso do smartphone, assunto das questões de número 29 a 33, os respondentes se posicionam discordantes das questões. Pode-se destacar a questão 30, que diz: "Sinto enorme desejo de usar meu smartphone novamente logo depois que eu parei de usá-lo", essa apresentou uma porcentagem expressiva de discordância total, $83,7 \%$ dos sujeitos não concordam.

Quadro 7 - Variáveis do SAS e frequência

\begin{tabular}{|c|c|c|c|c|c|c|c|}
\hline Variáveis & & $\begin{array}{l}\text { Frequência/ } \\
\text { Percentual }\end{array}$ & & & & & \\
\hline & & DT & D & DP & $C P$ & $C$ & CT \\
\hline \multirow[b]{2}{*}{26} & \multirow{2}{*}{$\begin{array}{l}\text { Prefiro falar com meus } \\
\text { amigos no smartphone do } \\
\text { que sair com meus amigos } \\
\text { na vida real ou com outros } \\
\text { membros da minha família. }\end{array}$} & 22 & 10 & 2 & 2 & 0 & 1 \\
\hline & & $59,5 \%$ & $27,0 \%$ & $5,4 \%$ & $5,4 \%$ & $0,0 \%$ & $2,7 \%$ \\
\hline \multirow[b]{2}{*}{27} & \multirow{2}{*}{$\begin{array}{l}\text { Prefiro pesquisar em meu } \\
\text { smartphone que perguntar } \\
\text { a outras pessoas. }\end{array}$} & 10 & 6 & 11 & 6 & 4 & 0 \\
\hline & & $27,0 \%$ & $16,2 \%$ & $29,7 \%$ & $16,2 \%$ & $10,8 \%$ & $0,0 \%$ \\
\hline \multirow{2}{*}{28} & \multirow{2}{*}{$\begin{array}{l}\text { Minha bateria totalmente } \\
\text { carregada não dura todo } \\
\text { o dia. }\end{array}$} & 9 & 9 & 5 & 5 & 8 & 1 \\
\hline & & $24,3 \%$ & $24,3 \%$ & $13,5 \%$ & $13,5 \%$ & $21,6 \%$ & $2,7 \%$ \\
\hline \multirow{2}{*}{29} & \multirow{2}{*}{$\begin{array}{l}\text { Uso meu smartphone mais } \\
\text { do que eu tinha intenção. }\end{array}$} & 9 & 16 & 3 & 6 & 3 & 0 \\
\hline & & $24,3 \%$ & $43,2 \%$ & $8,1 \%$ & $16,2 \%$ & $8,1 \%$ & $0,0 \%$ \\
\hline \multirow[b]{2}{*}{30} & \multirow{2}{*}{$\begin{array}{l}\text { Sinto enorme desejo de } \\
\text { usar meu smartphone } \\
\text { novamente logo depois que } \\
\text { eu parei de usá-lo. }\end{array}$} & 14 & 17 & 3 & 2 & 1 & 0 \\
\hline & & $37,8 \%$ & $45,9 \%$ & $8,1 \%$ & $5,4 \%$ & $2,7 \%$ & $0,0 \%$ \\
\hline \multirow[b]{2}{*}{31} & \multirow{2}{*}{$\begin{array}{l}\text { Tenho tentado diminuir } \\
\text { o tempo de uso de meu } \\
\text { smartphone várias vezes, } \\
\text { mas sempre falho. }\end{array}$} & 14 & 15 & 4 & 1 & 3 & 0 \\
\hline & & $37,8 \%$ & $40,5 \%$ & $10,8 \%$ & $2,7 \%$ & $8,1 \%$ & $0,0 \%$ \\
\hline \multirow[b]{2}{*}{32} & \multirow{2}{*}{$\begin{array}{l}\text { Sempre penso que devo } \\
\text { diminuir o tempo de uso do } \\
\text { meu smartphone. }\end{array}$} & 11 & 14 & 3 & 4 & 4 & 1 \\
\hline & & $29,7 \%$ & $37,8 \%$ & $8,1 \%$ & $10,8 \%$ & $10,8 \%$ & $2,7 \%$ \\
\hline \multirow[b]{2}{*}{33} & \multirow{2}{*}{$\begin{array}{l}\text { As pessoas ao meu redor } \\
\text { me dizem que eu uso } \\
\text { demais meu smartphone. }\end{array}$} & 18 & 9 & 5 & 5 & 0 & 0 \\
\hline & & $48,6 \%$ & $24,3 \%$ & $13,5 \%$ & $13,5 \%$ & $0,0 \%$ & $0,0 \%$ \\
\hline
\end{tabular}

Fonte: Dados da pesquisa.

Em suma, os resultados indicam que os colaboradores do sistema S não atingem altos níveis de dependência de smartphone, fator positivo tanto para a organização quanto para o indivíduo usuário. Dos 37 pesquisados, apenas 13 resultaram em um grau leve de dependência, o que não caracteriza-se como um dado negativo, somente como alerta para os próprios usuários. 
4.3 Análise dos resultados das entrevistas com dependentes de nível leve

O texto a seguir é baseado nas entrevistas realizadas com 3 dos 13 colaboradores do Sistema "S", identificados com grau leve de dependência e que se dispuseram a participar desta etapa. O grupo de entrevistados foi composto por 3 mulheres, com idades entre 23 e 40 anos e pode-se afirmar com base nos dados coletados na etapa quantitativa, que são indivíduos que utilizam o smartphone tanto para trabalho, como para lazer. As respondentes serão identificadas como R1 que possui 25 anos, R2 com idade de 23 anos e R3 de 40 anos de idade. As entrevistadas alcançaram, no questionário, pontuações iguais a 105, 76 e 90 de um total de 116 pontos possíveis para categoria leve, necessariamente na mesma ordem em que foram citadas. Corroborando com que Picon et al. (2015) afirma, as mulheres são usuárias prevalecentes dos smartphones.

A primeira questão abordada na entrevista procurou averiguar em que momento do dia a respondente começa a utilizar o smartphone, para qual fim ela utiliza e por que utiliza. A fala da R1 consegue esclarecer resumidamente esta questão: "Eu começo a utilizar o smartphone já à primeira hora da manhã (...) pra ver se tem alguma mensagem no Whatsapp ou se tem alguma mensagem na rede social, alguma notícia importante". As demais entrevistadas têm relatos parecidos a este aqui mencionado, sendo que a variável idade não influencia o tipo de uso do smartphone.

Quanto ao uso do smartphone nas tarefas profissionais as respondentes citaram a necessidade do aparelho para comunicação com os colegas, com clientes, para responder e-mails e para uso do Whatsapp, pois utilizam o aplicativo constantemente para comunicação no trabalho. Percebeu-se nos discursos que existe a necessidade, devido às funções que desempenham, que estejam sempre conectadas com seus smartphones. Além do uso profissional as respondentes disseram utilizá-lo para fins particulares no ambiente de trabalho.

Quando questionadas se o uso do smartphone já as prejudicou no trabaIho, relataram que, por vezes, o uso do aparelho afeta na concentração ao realizar tarefas, o que, consequentemente, pode prejudicar ou atrasar a entrega do trabalho realizado. Mark, Gudith e Klocke (2008), já citavam que a interrupção da concentração no trabalho, faz com que o profissional desenvolva uma habilidade de executar as tarefas de forma mais ágil, no sentido de compensar o tempo perdido quando interrompido, porém, a qualidade do trabalho pode ficar comprometida. Em relação a problemas de relacionamento com pessoas próximas, causados pelo uso do smartphone, a entrevistada (R1) que obteve a pontuação mais alta no instrumento de verificação de dependência, confessou que por vezes ela dá mais atenção para o aparelho que para as pessoas que estão a sua volta, mas ressaltou que isso nunca gerou nenhum problema grave. As demais disseram que não passaram por situações nesse sentido, a R2 
inclusive, enfatizou que fica irritada se presencia esse tipo de atitude. "Que eu me lembre, nunca tive problema de relacionamento com o uso do celular, eu só realmente acabo ficando um pouco irritada quando a pessoa "tá" usando bastante o celular enquanto eu "tô" com ela. Eu gosto de quando eu "tô" com a pessoa não ficar no celular, eu acho isso falta de respeito" (R2).

Questionadas sobre o controle do uso, se percebem quando o smartphone atrapalha e qual atitude tomam em relação a isso, as entrevistadas disseram ter total domínio, que sabem o momento em que devem usar e o momento em que não: "Não, nunca me atrapalhou assim em nenhuma situação, eu sei controlar bem o uso, eu sei a hora que eu devo pegar ele e utilizar e a hora que não" (R1). A fala da respondente 3, deixa bem clara a sua atitude quando o smartphone a atrapalha durante o trabalho: "Com certeza eu percebo se está me atrapalhando, por exemplo nos casos que falei de quando eu preciso concentração no trabalho, se "tá" me atrapalhando muito, eu desligo o celular" (R3). Nesses relatos, verifica-se que existe um domínio na forma e tempo de uso do smartphone, as entrevistadas conseguem abdicar do uso do aparelho, o que não ocorreria se a dependência apresentada fosse mais grave. O controle de uso e a consciência de que o aparelho está ou não atrapalhando, ocorre justamente devido ao fato de as três respondentes pertencerem ao nível leve de dependência.

Quanto aos sentimentos apontados pelas respondentes quando, por algum motivo, não conseguem utilizar o smartphone ou se conectar a internet através dele, pode-se destacar a ansiedade e nervosismo. As respondentes disseram sentir necessidade da conexão, de estarem "conectadas com o mundo". Para Won- Jun (2013), a dependência de smartphone pode ser determinada como uma condição de estar escravizado pelo aparelho e suas funções relacionadas, e isso justifica o sentimento percebido pelas entrevistadas em seus relatos. "Me dá um pouco de nervosismo, ansiedade, sabe?! Eu sinto uma sensação de que eu não "tô" conectada ao resto do mundo, sabe?! *risos*" (R3).

Finalmente, quanto aos sintomas físicos apresentados devido ao uso do smartphone, apenas uma delas disse não se recordar de ter sentido, acha que não utiliza tempo suficiente para que isso aconteça: "Nunca senti, que eu me lembre, eu acho que eu não utilizo períodos tão longos pra sentir dores por usar o celular" (R3). Todavia pode ocorrer de o usuário não relacionar a dor sentida ao uso, por não perceber a sua origem. As demais entrevistadas relataram sentir dores nos pulsos, na cabeça e nas costas.

É possível verificar nas falas das entrevistadas que o celular já faz parte de suas rotinas, que o uso é algo feito de forma costumeira quando se referindo a lazer. $O$ aparelho também é um instrumento indispensável profissionalmente para as respondentes, visto que nas empresas onde trabalham a ferramenta é utilizada como meio de comunicação, inclusive através do Whatsapp ou para acesso a e-mails, o que não dá a elas opção de escolha entre usar ou não o smartphone enquanto trabalham. Porém, verifica-se que o smartphone 
está inserido na vida das entrevistadas de tal forma que para elas é inevitável o uso diário do aparelho, porém, elas possuem grande controle sobre o uso, nesse sentido, é totalmente justificável que apresentem dependência leve de smartphone. Sobre a variável idade, tendo duas respondentes mais jovens, 23 e 25 anos, e outra com 40 anos de idade, pode-se afirmar que a faixa etária não influenciou em diferenças no modo de uso do smartphone no universo desta pesquisa. Percebe-se que neste contexto, tomado pela tecnologia, não há distinções entre idades, os novos hábitos tecnológicos foram adotados pelos indivíduos de forma geral.

\section{Considerações finais}

Estar conectado a todo o momento e em qualquer lugar é o que definitivamente atrai os usuários da tecnologia móvel por meio do smartphone. No entanto, deve-se controlar o tempo de uso, pois em excesso acaba por desencadear a dependência de smartphone por vezes grave, trazendo impactos negativos ao indivíduo. Para Ribeiro e Silva (2015), o fato de que as pessoas podem verificar e-mail, redes sociais, ver notícias online, enfim, manterem-se informadas de tudo com apenas poucos toques no smartphone é algo positivo, porém, esse universo leva a um ambiente favorável ao uso abusivo e a consequente dependência do aparelho.

Este estudo abordou a dependência de smartphone de forma descritiva, aprofundando

o tema quando verificados os impactos causados pelo uso abusivo de tal tecnologia nos colaboradores do Sistema " $\mathrm{S}$ " localizados em uma cidade do interior do Rio Grande do Sul. Foi possível identificar o perfil desses colaboradores quanto ao uso do smartphone, verificando um perfil em que a grande maioria são mulheres, nível de escolaridade alto, com idade média de 34 anos, casados e que utilizam o aparelho para trabalho e lazer, preponderantemente as redes sociais, bate-papo e e-mail. Pôde-se verificar também que a grande maioria dos participantes não são dependentes do uso do smartphone, porém, treze sujeitos acusaram nível leve de dependência.

Mesmo que o smartphone seja um facilitador da vida dos seus usuários, este dispositivo carrega consigo diversas ferramentas que permite sobrepor a esfera pessoal e profissional. Ao mesmo tempo em que o indivíduo está conectado em suas redes sociais para lazer, o mesmo pode receber a qualquer momento um e-mail urgente do trabalho. Tais características desse aparelho, não delimitam o tempo do trabalho e o não trabalho. Por consequência, o indivíduo pode estar prejudicando a qualidade do seu trabalho bem como, a qualidade do tempo de não trabalho, ou seja, o tempo de lazer.

Existem diversas estratégias adotadas pelas pessoas que percebem que o uso do smartphone deve ser controlado (CORSO, 2013). Pode-se usar da estratégia de desligar o celular ou desconectá-lo da internet enquanto está se 
fazendo uma atividade que necessite uma maior concentração, o que vai ao encontro de uma das estratégias de gerenciamento da tecnologia descrita por Mick e Fournier (1998). O indivíduo pode optar por deixar o aparelho guardado, ou nem o carregar, para não ter distrações e se dedicar totalmente a aproveitar um momento de lazer ou para melhorar seu desempenho no trabalho, o que configura uma estratégia de gerenciamento do espaço de uso ao se distanciar do aparelho para não o utilizar (MICK e FOURNIER, 1998). Obviamente, que estes indivíduos são notados como "diferentes", justamente por tentar limitar o uso do aparelho, mas essas ações otimizam o uso do tempo na esfera do trabalho ou na esfera pessoal. Essas medidas podem solucionar os problemas advindos do uso excessivo do aparelho como podem deixar seus usuários "para traz" na atualização dos acontecimentos diários.

É necessário que se tenha o autocontrole do uso do smartphone, mas é importante que haja um equilíbrio entre o tempo de usar e o de não fazer uso do aparelho, visto que esta é uma ferramenta muito presente no dia a dia das pessoas. E aqueles que não utilizam ou que utilizam demasiadamente podem ser prejudicados, socialmente, fisicamente e psicologicamente.

Quanto às contribuições desta pesquisa, pode-se destacar o trabalho de tradução do questionário SAS para o português e validação da mesma por dois especialistas da língua inglesa, uma vez que originalmente o questionário está disponível apenas em uma versão em inglês. No entanto, deve-se destacar que houve limitações nesta pesquisa quanto ao número de indivíduos participantes. O número de colaboradores que fizeram parte deste estudo representa em partes a realidade da população que compõem o Sistema "S", uma vez que não houve plena disponibilidade dos pesquisados em participar.

Para estudos futuros, sugere-se o desenvolvimento de pesquisas sobre este mesmo tema sendo realizadas com populações mais jovens, a fim de verificar se a incidência da dependência de smartphone nessa população tende a ser mais frequente e severa. Sugere-se também confrontar as diferentes faixas etárias, para realizar comparações com os resultados de estudos internacionais. Se torna interessante ainda, explorar a cultura do povo brasileiro como uma variável de influência no tipo de uso do smartphone, contribuindo assim, com a disseminação dessa temática em âmbito nacional.

\section{Referências bibliográficas}

BORGES, A. P; JOIA, L. A. Executivos e Smartphones: Uma relação ambígua e paradoxal. Revista Organizações e Sociedade, v.20, n.67, p.585-602, 2013.

GONÇALVES, A. P. B. Executivos, gênero e smartphones: uma exploração quanto aos paradoxos tecnológicos e às copying strategies. 2012. Tese de Doutorado em Administração de Empresas - Fundação Getúlio Vargas, Rio de Janeiro, 2012.

HOSPITAL SÍRIO LIBANÊS. Viver. Brasília: Ed. Letra a Letra, 2013. 
DEPENDÊNCIA DE SMARTPHONE: INVESTIGANDO A REALIDADE DE UMA PRESTADORA DE SERVIÇO DO SISTEMA "S"

IBGE. Cidades. 2016. Disponível em: http://cidades.ibge.gov.br/painel/painel.php?codmun=431710. Acesso em: 13 de outubro de 2016.

KWON M.; et al,. Development and Validation of a Smartphone Addiction Scale (SAS). Plos One, v. 8, n. 2, 2013.

KWON M. et al,. The Smartphone Addiction Scale: Development and Validation of a Short Version for Adolescents. Plos One, v. 8, n. 12, 2013.

LEMOS, A. Cibercultura e mobilidade: A era da conexão. Revista Razón y palavra, n. 41, 2004.

LOPEZ-FERNANDEZ, Olatz. Short version of the Smartphone Addiction Scale adapted to Spanish and French: Towards a cross-cultural research in problematic mobile phone use. Addictive Behaviors, v. 64, p. 275-280, 2017.

MARCONI, M. A. de; LAKATOS, E. M. Fundamentos de metodologia científica. São Paulo: Ed. Atlas S.A, 2009.

MARK, G; GUDITH, D; KLOKCE, U. The cost of interrupted work: more speed and stress. Berlin, 2008.

MICK, D. G.; FOURNIER, S. Paradoxes of technology: consumer cognizance, emotions and coping strategies. Journal of Consumer research, v. 25, n. 2, p. 123-143, 1998.

MOK, J. Y. et al. Latent class analysis on internet and smartphone addiction in college students. Dovepress, v. 10, p. 817-828, 2014.

ORLANDI, E. P. Análise de Discurso: Princípios e procedimentos. 5ed., Campinas, São Paulo: Pontes, 2003.

PICON, F. et al. Precisamos falar sobre tecnologia: Caracterizando clinicamente os subtipos de dependência de tecnologia. Revista Brasileira de Psicoterapia, v. 17, n. 2, p. 44-60, 2015.

RICHARDSON, J. R. et al. Pesquisa Social: Métodos e Técnicas. São Paulo: Ed. Atlas S. A, 2012.

ROCHA, A. V. F et al. Dependência Digital: Dá pra viver desconectado? In: EXPOSIÇÃO DA PESQUISA EXPERIMENTAL EM COMUNICAÇÃO, Uberlândia, 2015. Anais...Uberlândia: Sociedade Brasileira de Estudos Interdisciplinares da Comunicação,2015.

SEBRAE-RS. Institucional. 2016. Disponível em: < http://www.sebrae-rs.com.br/index.php/institucional>. Acesso em: 14 ago. 2016.

WON-JUN, L. An Exploratory Study on Addictive Use of Smartphone: Developing SAUS (Smartphone Addictive Use Scale). Journal of Convergence Information Technology, v. 8, n. 12, 2013.

YOUNG, K. S. Avaliação Clínica de clientes dependentes de internet. 2011. In: YOUNG, K. S; ABREU, C.N. (Org.); Dependência de Internet: Manual e guia de avaliação e tratamento. São Paulo: Ed. Artmed, 2011. 
FERNANDA DA CUNHA ORTEGA, KATHIANE BENEDETTI CORSO, MARTIELE GONÇALVES MOREIRA 